\title{
Cloud computing adoption reference model
}

\author{
Wan Abdul Rahim Wan Mohd Isa, Ahmad Iqbal Hakim Suhaimi, Nurulhuda Noordin, \\ Afdallyna Fathiyah Harun, Juhaida Ismail, Rosshidayu Awang Teh \\ Faculty of Computer and Mathematical Sciences, Universiti Teknologi MARA, Shah Alam, Malaysia
}

\begin{tabular}{|c|c|}
\hline Article Info & ABSTRACT \\
\hline Article history: & This paper presents a study to conceptualize a cloud computing adoption \\
\hline Received Jan 22, 2019 & reference model. The case study on the cloud computing adoption was done \\
\hline Revised Apr 28, 2019 & understand in-depth and real context phenomenon by investigating the \\
\hline Accepted May 17, 2019 & $\begin{array}{l}\text { influencing factors of cloud computing adoption. The main objective of this } \\
\text { study is to design a cloud computing adoption reference model. This study }\end{array}$ \\
\hline Keywords: & $\begin{array}{l}\text { applied Technology-Organizational-Environmental (TOE) Framework by } \\
\text { Tornatzky \& Fleischer and Diffusion of Innovation by Rogers as the }\end{array}$ \\
\hline Cloud & theoretical background of the Cloud Computing Adoption Reference. \\
\hline Cloud computing & $\begin{array}{l}\text { Ten interviews were conducted with key informants. The theme pattern } \\
\text { analysis of data were done by using qualitative computer programs, Atlas.ti. }\end{array}$ \\
\hline Cloud computing adoption & The findings are shown in summarize patterns that supports the \\
\hline Higher education institutions & conceptualization of cloud computing adoption reference model. Future work \\
\hline Malaysia & $\begin{array}{l}\text { include the adaption of cloud computing adoption reference model } \\
\text { specifically for the niche area of mobile computing. }\end{array}$ \\
\hline
\end{tabular}

Copyright () 2019 Institute of Advanced Engineering and Science. All rights reserved.

\section{Corresponding Author:}

Wan Abdul Rahim Wan Mohd Isa,

Faculty of Computer and Mathematical Sciences,

Universiti Teknologi MARA,

40450 Shah Alam, Selangor, Malayia.

Email:wrahim2@tmsk.uitm.edu.my

\section{INTRODUCTION}

An existence theory, model or framework are important to drive the research interest [1,2]. In order to gain understanding and derived the study of innovation technology adoption, theories are adapted to formulate conceptual framework of cloud computing adoption reference model. Diffusion of Innovation Theory (DOI), Theory Acceptance Model (TAM) and Technology-Organization-Environment framework have frequently used among researchers to explain technology innovation in ICT acceptance and adoption studies in organizations [3]. This study apply Technology-Organizational-Environmental (TOE) Framework by Tornatzky \& Fleischer [4] and Diffusion of Innovation by Rogers [5] as the theoretical background of the Cloud Computing Adoption Reference.

The TOE framework consists of three elements which are technological, organizational and environmental. The technological element associates with the process of adoption technology based on technology characteristics that influence the organization to adopt. Technological elements such as relative advantage, compatibility, complexity, trialability and observability were described the innovation technology [5] (Rogers, 2003). Roger's DOI theory focuses on ideas, processes, and technologies over time and space. The diffusion was defined by Rogers [5] (2003) as the process by communication among social system members via certain channels. Organizational focus on how organizational structure and process implemented towards the innovation. Meanwhile, environmental describes about external characteristics such as government regulations, competitors.

TOE framework used to identify several of adoption process such as adoption decision, techniques of evaluation, proof of concept, the implementation, the challenges, the impact and etc. The TOE framework 
widely used by [6-11] and the DOI theory widely used [12, 13]. Hence, the framework of adoption factors based on TOE and DOI were developed based on previous researcher's results as in Table 1, for gaining understanding of the adoption process of cloud computing adoption.

Table 1. Factors of Cloud Computing Adoption

\begin{tabular}{|c|c|c|c|c|c|c|c|c|c|c|c|c|c|c|}
\hline $\begin{array}{l}\text { Framework/Model/ } \\
\text { General Concept }\end{array}$ & 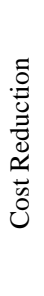 & 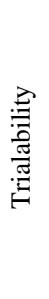 & 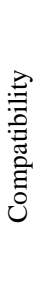 & 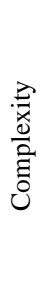 & 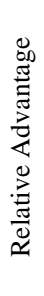 & 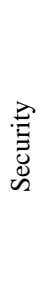 & 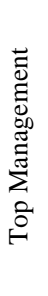 & 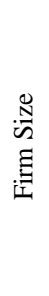 & 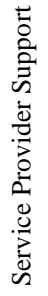 & 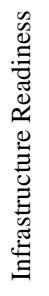 & 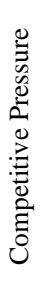 & 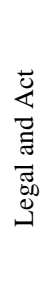 & References & Domain \\
\hline TOE & $\mathrm{X}$ & & & & & $\mathrm{X}$ & $\sqrt{ }$ & & $\sqrt{ }$ & & & & [6] & Education \\
\hline TOE, DOI & & $\sqrt{ }$ & & $\sqrt{ }$ & & & $\sqrt{ }$ & & & $\sqrt{ }$ & & & [7] & SME \\
\hline DOI & & $\sqrt{ }$ & $\sqrt{ }$ & $\sqrt{ }$ & $\sqrt{ }$ & & & & & & & & [12] & SME \\
\hline TOE & & $\sqrt{ }$ & $\sqrt{ }$ & $\mathrm{X}$ & & & $\sqrt{ }$ & & & & & & [14] & Government \\
\hline TOE, DOI & & & $\sqrt{ }$ & $\sqrt{ }$ & $\sqrt{ }$ & $\sqrt{ }$ & $\sqrt{ }$ & & & $\mathrm{X}$ & & & [8] & Government \\
\hline TOE & & & $\mathrm{X}$ & $\mathrm{X}$ & $\mathrm{X}$ & & $\sqrt{ }$ & $\sqrt{ }$ & & $\mathrm{X}$ & $\sqrt{ }$ & & [9] & SME \\
\hline TOE & & $\sqrt{ }$ & $\sqrt{ }$ & $\sqrt{ }$ & $\sqrt{ }$ & $\sqrt{ }$ & & & & & & $\sqrt{ }$ & [15] & Education \\
\hline TOE & $\sqrt{ }$ & $\sqrt{ }$ & $\sqrt{ }$ & & & & $\sqrt{ }$ & & & $\sqrt{ }$ & & & [11] & SME \\
\hline General Concept & & & & & & & & & & $\sqrt{ }$ & & & [16] & Education \\
\hline DOI & & $\mathrm{X}$ & $\sqrt{ }$ & $\mathrm{X}$ & $\sqrt{ }$ & & & & & & & & [13] & Government \\
\hline TOE & & & & & $\sqrt{ }$ & & $\sqrt{ }$ & & & & & & {$[17]$} & SME \\
\hline General concept & & & $\mathrm{X}$ & $\mathrm{X}$ & $\sqrt{ }$ & & $\mathrm{X}$ & & & & $\sqrt{ }$ & & [18] & Education \\
\hline TOE & $\sqrt{ }$ & & & & & $\sqrt{ }$ & $\sqrt{ }$ & $\sqrt{ }$ & & & $\sqrt{ }$ & & [19] & Health \\
\hline TOE & & & $\mathrm{X}$ & $\sqrt{ }$ & $\mathrm{X}$ & & & $\sqrt{ }$ & $\mathrm{X}$ & $\sqrt{ }$ & & & [20] & Education \\
\hline General concept & $\sqrt{ }$ & & & & $\sqrt{ }$ & $\sqrt{ }$ & & & & & & $\sqrt{ }$ & [21] & Enterprise \\
\hline Total & 3 & 5 & 6 & 5 & 7 & 4 & 8 & 3 & 1 & 4 & 3 & 2 & & \\
\hline
\end{tabular}

Note

$\sqrt{ }$ : illustrates significant factors towards cloud computing adoption in certain organization

$\mathrm{X}$ : illustrates insignificant factors towards cloud computing adoption in certain organization

The main objective of this study is to design a cloud computing adoption reference model. Ten interviews were conducted with key informants. The analysis of data were done by using qualitative computer programs, Atlas.ti version 7. The findings are shown in summarize patterns that supports the conceptualization of cloud computing adoption reference model.

\section{RESEARCH METHOD}

The main objective of this study is to design a cloud computing adoption reference model. Ten interviews were conducted with key informants. The theme pattern analysis of data were done by using qualitative computer programs, Atlas.ti version 7. In this study, multiple themes would produce similar or difference factors due to many stages of cloud computing deployment and service models. The pattern match would be used to compare the identified values and match. Procedure applied when using computer-assisted tool (Atlas.ti version 7).

\section{RESULTS}

The pattern matching analysis technique has been adopted during validation phase. The purpose is to compare the identified factor whether there are patterns styles among themes. The triangulation methodological was produced strong confirmation to the identified factors of cloud computing adoption for one of the local public university in Malaysia. There were five themes developed from the analysis. The themes illustrated overall landscape of this study and inter relation of the factors. There were four primary categories for the themes which were technological, organizational, environmental and social. Theme 1 (influencing factors of cloud computing adoptions) consists of 17 factors and Theme 2 (main influencing factors of cloud computing adoptions) illustrates three main factors that influence the informants. The primary factors were highlighted by the informants which were cost reduction, relative advantage and guideline and policy as illustrated in Themes 2 . 
The advantages of cloud computing adoption by the local public university had been illustrated in Theme 3. The advantages perceived higher benefit on relative advantage, cost reduction and social (reputation). There were eight challenges of cloud computing adoptions concerned by the informants as listed in Theme 4. Theme 5 reflects recommendations for cloud computing adoption reference model. There are other studies indicated that various elements were concerned and influenced other organizations to adopt with the cloud computing technology $[6,20,15,7,8,19]$. Table 2 summarize the pattern existed in Theme 1 until Theme 5. At the end of interviews, the researcher also gained opinions and recommendations from the informants on the elements that they wanted to recommend to be part of the cloud computing adoption reference model. The recommendations described from their experiences, intentions as well as the best practices that they have considered. The recommendations have been organized and pattern matching analysis applied.

Additionally, the themes triangulation has aided the researcher in order to conform the themes validity, meaningful result and contribute better understanding phenomenon [22]. According to Low, Chen, and $\mathrm{Wu}$ (2011) [9] the organization decision of technology adoption also influenced by the advantages and challenges of the technology towards the organization. All the codes from Themes 1 until Theme 5 were taken into consideration to conform and validate the factor that influenced the organization to adopt the cloud computing technology. Therefore, the example of influencing factors of cloud computing adoption for one of the local public university were relative advantages, cost reduction, ease of use, compatibility, trialability, operational requirement, system nature, cloud deployment model, sustainability, top management, cost benefit analysis, infrastructure readiness, service level agreement, geographical, governance and reputation. Whereas the example of challenges such as knowledge and IT skill set, financial, data privacy, security, cloud service provider, legal and act, guideline and policy also influenced the organization in the decision to adopt the cloud computing technology.

Table 2. Themes pattern analysis

\begin{tabular}{|c|c|c|c|c|c|}
\hline Category and Coding Unit & Theme 1 & Theme 2 & Theme 3 & Theme 4 & Theme 5 \\
\hline \multicolumn{6}{|l|}{ Technological } \\
\hline Relative advantage & $\sqrt{ }$ & $\sqrt{ }$ & $\sqrt{ }$ & & $\sqrt{ }$ \\
\hline Cost reduction & $\sqrt{ }$ & $\sqrt{ }$ & $\sqrt{ }$ & & \\
\hline Ease of use & $\sqrt{ }$ & & & & \\
\hline \multicolumn{6}{|l|}{ Complexity } \\
\hline Compatibility & $\sqrt{ }$ & & & & \\
\hline Trialability & $\sqrt{ }$ & & & & \\
\hline \multicolumn{6}{|l|}{ Operational Requirement } \\
\hline Security & $\sqrt{ }$ & & & $\sqrt{ }$ & $\sqrt{ }$ \\
\hline \multicolumn{6}{|l|}{ System Nature } \\
\hline \multicolumn{6}{|l|}{ Cloud Deployment Model } \\
\hline Sustainability & $\sqrt{ }$ & & & & \\
\hline Technical & & & & $\sqrt{ }$ & \\
\hline \multicolumn{6}{|l|}{ Organizational } \\
\hline Top management & $\sqrt{ }$ & & & & \\
\hline Financial & $\sqrt{ }$ & & & $\sqrt{ }$ & \\
\hline Cost Benefit Analysis & & & & & $\sqrt{ }$ \\
\hline Infrastructure readiness & $\sqrt{ }$ & & & & \\
\hline Knowledge and IT skill set & $\sqrt{ }$ & & & $\sqrt{ }$ & $\sqrt{ }$ \\
\hline \multicolumn{6}{|l|}{ Environmental } \\
\hline Cloud Service Provider & $\sqrt{ }$ & & & $\sqrt{ }$ & \\
\hline Service Level Agreement (SLA) & $\sqrt{ }$ & & & & $\sqrt{ }$ \\
\hline Data Privacy & $\sqrt{ }$ & & & $\sqrt{ }$ & \\
\hline Geographical & $\sqrt{ }$ & & & & \\
\hline \multicolumn{6}{|l|}{ Governance } \\
\hline Guideline and Policy & $\sqrt{ }$ & $\sqrt{ }$ & & $\sqrt{ }$ & $\sqrt{ }$ \\
\hline \multicolumn{6}{|l|}{ Legal and Act } \\
\hline \multicolumn{6}{|l|}{ Social } \\
\hline Reputation & & & $\sqrt{ }$ & & \\
\hline
\end{tabular}

\section{CLOUD COMPUTING ADOPTION MODEL}

The cloud computing adoption reference model as in Figure 1 was created based on theme triangulation and pattern matching analysis result as discussed. In-depth contemporary phenomenon study has gathered relevant information about the influence factors, challenges concerned, and advantage gained, as well as informants' recommendation elements to be part of the cloud adoption reference model. 


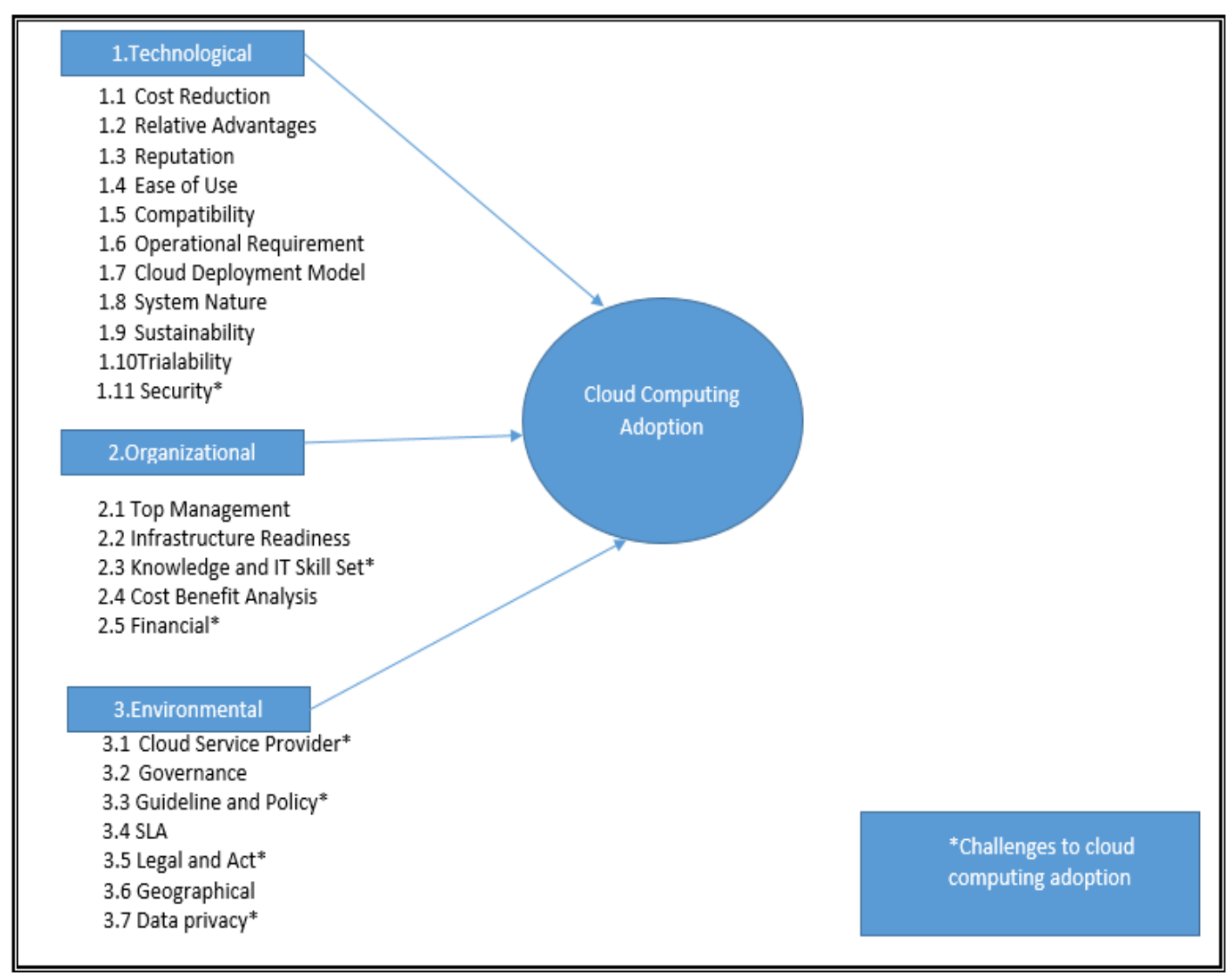

Figure 1. Cloud computing adoption reference model

The cloud computing adoption reference model Figure 1 was designed based on certain justifications. The justifications being made based on researcher's analysis, findings and personal view. According to Creswell (2012) [1], interpretation for qualitative research require steps back, forms personnel view based analysis and finding as well as comparison with the past studies.

There were twenty-three factors that influenced the organization to adopt and to be part of cloud computing reference model as shown in Figure 1. The factors were cost reduction, relative advantages, reputation, ease of use, compatibility, operational requirement, cloud deployment model, system nature, sustainability, trialability, top management, infrastructure readiness, cost benefit analysis, governance, SLA and geographical. Figure 1 also indicated security, knowledge and IT skill set, financial, cloud service provider, guideline and policy, legal and act and data privacy became challenges towards the adoption of the technology to the organization. The four influence factors that also became challenges were financial, legal and act, data privacy and guideline and policy have been highly stressed by top management informants. Hence, from the researcher personal of view the four-factor became primary and part of the challenges for the adoption process.

\section{CONCLUSION}

As a conclusion, the cloud computing adoption reference model can be recommended as guidance for effective adoption and implementation in future. The slow adoption issue may be reduced by knowing and understanding the influencing factors during the adoption process. For example, proper planning and conducting cloud adoption analysis based on the identified factors would help the organization to choose suitable deployment and service model as well as the cloud provider. Besides, unsustainability operational cost and data privacy issue may also be reduced by understanding the resources capability in terms of knowledge and IT skill set, budget and financial level by performing cost benefit analysis and develop internal cloud governance. The cloud governance can be initiated by creating guideline and policy, negotiating and having clear SLA, investigating about legal and act, data geographical and level of data privacy impact. There are growing research on blended learning, online learning and mobile learning 
adoption for Higher Education Institutions in Malaysia [23-29]. The Malaysia Education Blueprint 20152025 roadmap towards higher income nation by producing holistic, excellent graduates and lifelong learners through independent and democratize access towards learning when higher education institutions adopted cloud computing services as the universities' IT service platform.

\section{ACKNOWLEDGEMENTS}

This research is funded by the Research Entity Initiative (REI), Universiti Teknologi MARA, Malaysia (Project Code: 600-IRMI/REI 5/3 (013/2018).

\section{REFERENCES}

[1] J. W. Creswell, "Mixed methods designs". In P. A. Smith, C. Robb, M. Buchholtz, \& K. Mason (Eds.), Educational research: Planning, conducting, and evaluating quantitative and qualitative research, pp. 534-575, Boston, MA: Pearson, 2012.

[2] R. K. Yin, Case study research: design and methods, SAGE Publications, Inc, 2012.

[3] R. F. El-Gazzar, "A Literature Review on Cloud Computing Adoption Issues in Enterprises". In: Bergvall-Kåreborn B., Nielsen P.A. (eds) Creating Value for All Through IT. TDIT 2014. IFIP Advances in Information and Communication Technology, vol 429. Springer, Berlin, Heidelberg, 2014.

[4] L. G. Tornatzky and M. Fleischer, The Processes of Technological Innovation. Lexington Books, Lexington, Massachusetts, 1990.

[5] E. M. Rogers, Diffusion of Innovations, The Free Press, New York, 1995.

[6] N. Gupta and S. Thakur, S., "The factors affecting adoption of cloud computing technology", International Journal of Advanced Research in Computer and Communication Engineering, vol. 3, no. 6, pp. 7229-7235, 2014.

[7] S. R. Tehrani, and F. Shirazi, F., "Factors influencing the adoption of cloud computing by small and medium size enterprises (smes)", International Journal of Emerging Science and Engineering (IJESE), vol. 2, pp. 631-642, 2014.

[8] M. A. Wahsh, and J. S. Dhillon, "An investigation of factors affecting the adoption of cloud computing for Egovernment implementation", 2015 IEEE Student Conference on Research and Development (SCOReD), pp. 323$328,2015$.

[9] C. Low, Y. Chen, and M. Wu, M., "Understanding the determinants of cloud computing adoption", Industrial Management \& Data Systems, vol. 111, no. 7, pp. 1006-1023, 2011.

[10] S. A. Mokhtar, S. H. Shaikh Ali, A. Al-Othman, and A. Al-Sharafi, A., "Identifying the determinants of cloud computing adoption in higher education institutions," 2016 International Conference on Information and Communication Technology (ICICTM), pp. 115-119, 2016.

[11] E. O. Yeboah-Boateng, and K. A. Essandoh, "Factors influencing the adoption of cloud computing by small and medium enterprises in developing economies," International Journal of Emerging Science and Engineering (IJESE), vol. 2, no. 4, pp. 13-20, 2014.

[12] A. Lin, and N. C. Chen, "Cloud computing as an innovation: perception, attitude, and adoption", International Journal of Information Management, vol. 32, no. 6, pp. 533-540. 2012.

[13] H. Sallehudin, R. C. Razak, and M. Ismail, M., "Factors influencing cloud computing adoption in the public sector: an empirical analysis", Journal of Entrepreneurship and Business, vol. 3, no. 1, pp. 30-45. 2015.

[14] H. Sallehudin, R. C. Razak, and M. Ismail, M., "Determinants and impact of cloud computing implementation in the public sector," Journal of Advances in Information Technology, vol. 7, no. 4, pp. 245-251. 2016.

[15] L. Morgan, and K. Conboy, "Factor affecting the adoption of cloud computing: an exploratory study", Proceedings of the 21st European Conference on Information Systems, pp. 1-12. 2013.

[16] N. Sultan, "Cloud computing for education: a new dawn?", International Journal of Information Management, vol. 30, no. 2, pp. 109-116. 2010.

[17] H. P. Borgman, B. Bahli, H. Heier, and F. Schewski, "Cloudrise: exploring cloud computing adoption and governance with the toe framework", Proceedings of the Annual Hawaii International Conference on System Sciences, pp. 4425-4435, 2013.

[18] A. Tashkandi, and I. Al-Jabri, I. "Cloud computing adoption by higher education institutions in saudi arabia: analysis based on toe," 2015 International Conference on Cloud Computing (ICCC), pp. 1-8, 2015.

[19] N. Zainuddin, N. Maarop, W. Z. Abidin, N. F. Azmi, and G. N. Samy, "Cloud computing adoption conceptual model of malaysian hospitals", Open International Journal of Informatics, vo. 3, no. 1, pp. 1-10, 2015.

[20] W. Klug, "Factors affecting cloud computing adoption among universities", Issues in Information Systems, vo. 16, no. 3, pp. 1-10, 2015.

[21] M. G. Avram, "Advantages and challenges of adopting cloud computing from an enterprise perspective", Procedia Technology, vol. 12, pp. 529-534, 2014.

[22] K. Jonsen, and K. A Jehn, "Using triangulation to validate themes in qualitative studies", Qualitative Research in Organizations and Management: An International Journal, vol. 4, no. 2, pp. 123-150, 2009.

[23] W. A. R. Wan Mohd Isa, A. Mohd Lokman, I. N. Mat Sah, A. R. Hamdan, and J. E. Luaran, "Framing grounded theory method (gtm) in blended learning adoption patterns: a research framework," Advanced Science Letters, American Scientific Publisher, vol. 22, no. 10, pp. 3011-3013, 2016. 
[24] W. A. R. Wan Mohd Isa, A. Mohd Lokman, J. E. Luaran, M. N. Mustapa, I. N. Mat Sah, A. R. Hamdan, "Exploring new factors for m-learning adoption in blended learning environment," Information Journal, International Information Institute, vol. 19, no 10, pp. 4743-4747, 2016.

[25] W. A. R. Wan Mohd Isa, A. Mohd Lokman, M. R. Megat Adnan, I. N. Mat Sah, A. R. Hamdan, and J. E. Luaran, "Assessing m-learning readiness in blended learning environment: an empirical investigation", Advanced Science Letters, American Scientific Publisher, vol. 22, no. 10, pp. 3151-3154, 2016

[26] W. A. R. Wan Mohd Isa, A. Mohd Lokman, M. R. Megat Adnan, I. N. Mat Sah, A. R. Hamdan, and J. E. Luaran, "Factors of using m-learning in blended learning environment: a qualitative inquiry," Advanced Science Letters, American Scientific Publisher, vol. 22, no. 10, pp. 3155-3158, 2016.

[27] W. A. R. Wan Mohd Isa, "A conceptual model of m-learning adoptions," ARPN Journal of Engineering and Applied Sciences, vol. 11, no. 3, pp. 1978-1982, 2016.

[28] R. Abdul Majid, and J. Che Hasim, "The effectiveness of frog vle implementation: students' perspective," Indonesian Journal of Electrical Engineering and Computer Science, vol. 14, no. 1, pp. 381-387, 2019.

[29] F. Redzuan, A.-N. A. Khairuddin, and N. A. Daud, "Emotional augmented reality-based mobile learning design elements: a kansei engineering approach," Indonesian Journal of Electrical Engineering and Computer Science, vol. 14, no. 1, pp. 413-420, 2019. 